\title{
Desempenho produtivo de vacas da raça Gir leiteira em confinamento alimentadas com níveis de concentrado e proteína bruta nas dietas ${ }^{1}$
}

\author{
Rafael Monteiro Araújo Teixeira ${ }^{2}$, Rogério de Paula Lana ${ }^{3}$, Leonardo de Oliveira \\ Fernandes ${ }^{4}$, André Soares de Oliveira ${ }^{2}$, Augusto César de Queiroz ${ }^{2}$, Joabe Jobson de \\ Oliveira Pimentel ${ }^{2}$
}

\author{
1 Pesquisa financiada pela FAPEMIG. \\ 2 Departamento de Zootecnia - UFV. \\ ${ }^{3}$ Departamento de Zootecnia - UFV. Bolsista do CNPq. Membro do INCT-CA. \\ ${ }^{4}$ EPAMIG - Uberaba, MG.
}

\begin{abstract}
RESUMO - Objetivou-se avaliar o efeito de níveis crescentes de concentrado e de proteína bruta em dietas sendo avaliado o consumo de matéria seca e de nutrientes, coeficientes de digestibilidades, produção e composição do leite e eficiência de utilização de alimentos. Vinte vacas em lactação foram distribuídas em delineamento em blocos casualizados, com cinco repetições por dieta, definidas conforme a produção de leite. As dietas experimentais foram constituídas de silagem de sorgo como volumoso e concentrado nos níveis de 11,7; 23,3; 35,2; e 46,8\%, com quatro níveis de proteína bruta (PB) (11,0; 12,0; 14,0; e 16,0\%), com base da MS da dieta. Aumentos nos níveis de concentrado e de proteína bruta levaram a maior aumento no consumo de matéria seca total. O coeficiente de digestibilidade da proteína bruta foi influenciado pelos maiores níveis de concentrado e proteína bruta da dieta. A produção de leite foi maior nas vacas alimentadas com as dietas com maior nível de concentrado e PB, mas não diferiu entre as vacas que receberam as dietas intermediárias. Para vacas Gir linhagem leiteira mantidas nas condições desta pesquisa, níveis de $23,3 \%$ de concentrado e $12,0 \%$ de proteína bruta na dieta proporcionam melhor resposta produtiva.
\end{abstract}

Palavras-chave: digestibilidade, eficiência, leite, zebu

\section{Productive performance of dairy Gyr cows in feedlot fed levels of concentrate and crude protein in diets}

\begin{abstract}
The objective of this work was to evaluate the effect of increasing levels of concentrate and crude protein in the diets, in which intakes of dry matter and nutrients, coefficients of digestibility, milk production and composition and efficiency of food use were evaluated. Twenty cows in lactation were distributed in a random block design, with five replicates per diet, defined according to milk production. The experimental diets were constituted of sorghum silage as roughage and concentrate at the following levels: $11.7 ; 23.3 ; 35.2$ and $46.8 \%$ with four levels of crude protein (CP) $(11.0 ; 12.0 ; 14.0$ and $16.0 \%)$ on diet dry matter basis. Increases in the levels of concentrate and crude protein caused a greater increase in the total dry matter intake. The coefficient of digestibility of crude protein was influenced by greater levels of concentrate and crude protein in the diet. Milk production was greater for cows fed diets with greater levels of concentrate and crude protein but it did not differ among cows fed other diets. For cows of milking Gyr breed kept in the conditions of this research, levels of $23.3 \%$ concentrate and $12 \%$ of crude protein in the diet present the best productive response.
\end{abstract}

Key Words: digestibility, efficiency, milk, zebu

\section{Introdução}

O aumento da produtividade leiteira é de grande interesse de produtores, técnicos e pesquisadores e está na dependência de fatores genéticos, sanitários, ambientais, nutricionais e suas interações. Os sistemas nutricionais correntes utilizados por nutricionistas foram gerados a partir de dados provenientes de países de clima temperado como Estados Unidos (NRC, 1989 e 2001) e Inglaterra
(ARC, 1980), os quais podem diferir das condições vigentes no ambiente tropical.

No Brasil, país tropical, as vacas da raça Gir linhagem leiteira tem sido preferencialmente utilizada em cruzamento com gado leiteiro europeu. Assim, faz-se necessário entender as respostas produtivas destes animais à utilização de nutrientes. No entanto, pesquisas com vacas da raça Gir linhagem leiteira são escassas, notadamente sobre a suplementação com alimentos concentrados, os quais 
apresentam repostas decrescentes da produção de leite com outros grupos genéticos em função do aumento no consumo de concentrado (Bargo et al., 2003; Lana et al., 2005; Oliveira et al., 2007).

Objetivou-se avaliar o efeito de níveis crescentes de concentrado e de proteína bruta em dietas de vacas da raça Gir Leiteiro mantidas sob confinamento no período seco do ano sob o consumo de matéria seca e de nutrientes, coeficientes de digestibilidades, produção e composição do leite e eficiência de utilização de concentrados.

\section{Material e Métodos}

Vinte vacas da raça Gir Leiteiro em lactação, multíparas, com peso médio de $418 \mathrm{~kg}$, condição de escore corporal de 5,0 numa escala de 0 a 9 (Ferreira et al., 2005), produção de leite média de 14,5 kg e em média 62 dias de lactação (mínimo de 45 dias e máximo de 93 dias de lactação), foram distribuídas em delineamento em blocos casualizados, com cinco repetições por tipo de dieta testada, sendo os blocos formados em função da produção de leite. O experimento foi conduzido durante três períodos experimentais de 21 dias cada, do dia 5 de agosto a 7 de outubro de 2005, totalizando 63 dias na unidade experimental da EPAMIG em Uberaba, Minas Gerais.

As dietas experimentais foram constituídas de silagem de sorgo como volumoso e concentrado nos níveis de 11,7; 23,3; 35,2; ou 46,8\% com quatro de proteína bruta $(11,0$; 12,0; 14,0; e 16,0\%), com base da MS da dieta (Tabelas 1 e 2). As dietas foram ofertadas duas vezes ao dia, metade após a ordenha da manhã e a outra metade após a ordenha da tarde, de forma completa, permitindo sobras de até $10,0 \%$ da matéria seca ofertada.

As vacas foram alojadas em baias individuais, com cochos individuais de madeira e bebedouros automáticos de concreto. As baias possuíam aproximadamente $10 \mathrm{~m}^{2} \mathrm{de}$ área sob chão de terra batida e, por serem desprovidas de

Tabela 1 - Proporção de ingredientes das rações concentradas das dietas experimentais (\% da MS)

\begin{tabular}{lcccc}
\hline & \multicolumn{4}{c}{ Níveis de concentrado e proteína bruta } \\
\cline { 2 - 5 } Item & $11,7: 11$ & $23,3: 12$ & $35,2: 14$ & $46,8: 16$ \\
\hline Milho & 31,6 & 60,7 & 63,7 & 67,3 \\
Farelo de soja & 51,3 & 30,8 & 30,6 & 28,5 \\
Ureia & 7,29 & 3,87 & 2,61 & 1,89 \\
Sulfato de amônia & 0,81 & 0,43 & 0,29 & 0,21 \\
Sal mineral 1 & 8,6 & 4,3 & 2,9 & 2,1 \\
Total & 100,0 & 100,0 & 100,0 & 100,0 \\
\hline${ }^{1}$ Ca - 15,6\%; P - 5,1\%; S - 2,0\%; Mg - 3,3\%; Na - 9,3\%; K - 2,82\%; Co - 0,003\%; \\
Cu - 0,040\%; Cr - 0,001\%; Fe - 0,2\%; I - 0,004\%; Mn - 0,135\%; Se - 0,002\%; \\
F - 0,051\%; Zn - 0,170\%; vitamina A - 135.000,00 UI; vitamina D3 - \\
68.000,00 U.I.; vitamina E - 450,00 UI. Solubilidade do fósforo de 95\%.
\end{tabular}

cobertura, foram dotadas de sombrite para melhor conforto dos animais.

A pesagem dos animais, a avaliação da condição de escore corporal e a amostragem do leite foram feitas a cada 21 dias, em um único dia, pela manhã e à tarde. As estimativas do consumo de matéria seca foram feitas diariamente ao longo dos 63 dias através de pesagens da quantidade de alimentos fornecidos e das sobras de cada animal. Durante o período experimental, foram feitas amostragens dos alimentos e sobras que foram acondicionadas em sacos plásticos e armazenadas em congelador a $-10^{\circ} \mathrm{C}$ para posteriores análises. Ao final de cada período de 21 dias, essas amostras foram misturadas e elaboradas uma amostra composta por animal.

As amostras de silagem de sorgo, ingredientes da ração concentrada, sobras e fezes foram pré-secas em estufas de ventilação forçada a $65^{\circ} \mathrm{C}$, durante 72 horas. Em seguida, foram homogeneizadas e processadas em moinho tipo Willey, utilizando peneira com malha de $1 \mathrm{~mm}$. As análises de matéria seca (MS), matéria orgânica (MO), compostos nitrogenados totais, fibra em detergente neutro (FDN), fibra em detergente ácido (FDA), lignina, extrato etéreo (EE), compostos nitrogenados insolúveis em detergente neutro (NIDN), nitrogênio insolúveis em detergente ácido (NIDA) e minerais foram realizadas segundo os procedimentos descritos por Silva \& Queiroz (2002). Os compostos nitrogenados não proteicos foram determinados segundo Licitra et al. (1996), enquanto os teores de carboidratos totais (CHO) foram calculados segundo Sniffen et al. (1992): $\mathrm{CHO}=100-(\% \mathrm{~PB}+\% \mathrm{EE}+\%$ Cinzas $)$, sendo os teores de carboidratos não-fibrosos (CNF) obtidos pela fórmula $\mathrm{CNF}=\mathrm{CHO}-\mathrm{FDN}$.

Na metade do segundo período experimental foi feita a coleta de fezes durante seis dias consecutivos, de 26 em 26 horas, efetuadas diretamente no reto. As amostras de fezes foram acondicionadas em sacos plásticos devidamente etiquetados, e armazenadas em congelador a $-10^{\circ} \mathrm{C}$. Ao final do período de coletas, as amostras de fezes de cada animal

Tabela 2 - Proporção de ingredientes das dietas experimentais

\begin{tabular}{|c|c|c|c|c|}
\hline \multirow[b]{2}{*}{ Item } & \multicolumn{4}{|c|}{ vel de concentrado:proteína bruta (\% da MS) } \\
\hline & $11,7: 11$ & $23,3: 12$ & $35,2: 14$ & $46,8: 16$ \\
\hline Silagem de sorgo & 88,3 & 76,6 & 65,0 & 53,3 \\
\hline Milho & 3,7 & 14,2 & 22,3 & 31,4 \\
\hline Farelo de soja & 6,0 & 7,2 & 10,7 & 13,3 \\
\hline Ureia + sulfato de amônia & 1,0 & 1,0 & 1,0 & 1,0 \\
\hline Sal mineral & 1,0 & 1,0 & 1,0 & 1,0 \\
\hline Total & 100,0 & 100,0 & 100,0 & 100,0 \\
\hline $\begin{array}{l}\text { Relação volumoso: } \\
\text { concentrado }\end{array}$ & $88,3: 11,7$ & $76,7: 23,3$ & $65,0: 35,0$ & $53,2: 46,8$ \\
\hline
\end{tabular}


Tabela 3 - Composição química da silagem de sorgo e das dietas experimentais

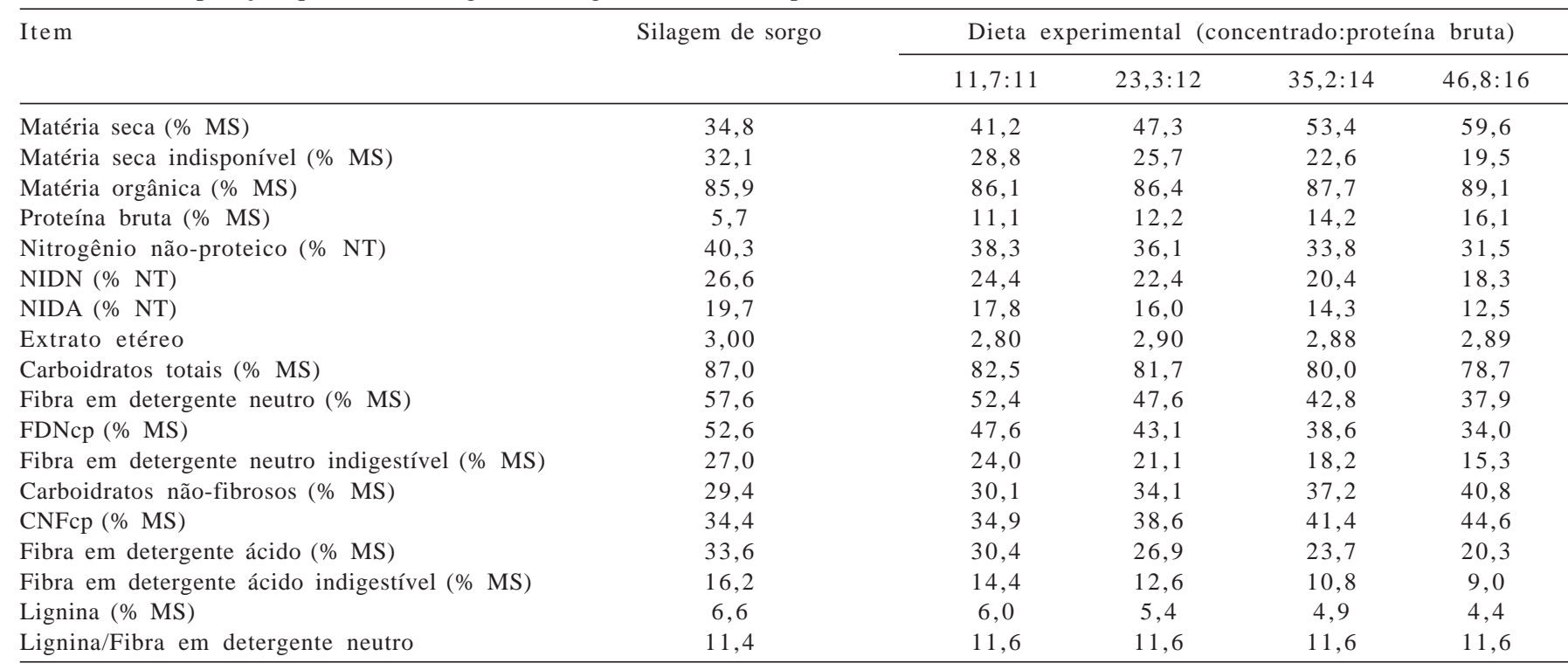

NNP = compostos nitrogenados não-proteicos; NIDN = nitrogênio insolúvel em detergente neutro; NIDA = nitrogênio insolúvel em detergente ácido; FDNcp = fibra em detergente neutro corrigida para cinzas e proteína; $\mathrm{CNFcp}$ = carboidratos não-fibrosos corrigidos para cinzas e proteína.

em cada período foram pré-secas e moídas, sendo obtida uma amostra composta por animal, com base no peso seco de cada subamostra. Foram retiradas amostras de sobras e alimentos fornecidos durante o período de coleta de fezes.

A estimativa da excreção fecal foi efetuada, através do indicador interno fibra em detergente neutro indisponível (FDNi), obtidos após incubação ruminal in situ utilizando-se sacos F57 (Ankon ${ }^{\circledR}$ ). Os sacos apresentavam dimensão de $4 \times 5 \mathrm{~cm}$, sendo que as alíquotas acondicionadas obedeceram à relação de $27 \mathrm{mg}$ de matéria seca por centímetro quadrado de superfície.

Os sacos foram incubados por 264 horas (Casali et al., 2008) no rúmen de uma novilha mestiça. Posteriormente, os sacos foram retirados, lavados com água corrente até o total clareamento desta, secados em estufa de ventilação forçada $\left(60^{\circ} \mathrm{C} / 72\right.$ horas) e, seqüencialmente, em estufa nãoventilada $\left(105^{\circ} \mathrm{C} / 45\right.$ minutos $)$, acondicionados em dessecador e pesados, sendo encontrado o teor de matéria seca indisponível (MSi) e, então, foram tratados com detergente neutro, na proporção de $50 \mathrm{~mL}$ por saco. Após esse procedimento, seguiram-se os mesmos protocolos no uso de estufas, dessecadores e balanças, sendo o resíduo considerado como fibra em detergente neutro indisponível (Cochran et al., 1986).

Os valores de nutrientes digestíveis totais das dietas foram calculados pela seguinte equação: NDTobs $=$ PBD + $(\mathrm{EED} \times 2,25)+\mathrm{FDND}+\mathrm{CNFD}$, em que PBD = proteína bruta digestível; $\mathrm{EED}=$ extrato etéreo digestível; FDND = fibra em detergente neutro digestível; e CNFD = carboidratos nãofibrosos digestíveis.
A avaliação da produção de leite foi efetuada no início, no meio e no final do período experimental através do controle leiteiro oficial da Associação Brasileira dos Criadores de Zebu (ABCZ). Como se tratava de vacas da raça Gir linhagem leiteira há necessidade da presença do bezerro na sala de ordenha para estimular as vacas a descerem o leite. Dessa forma, o manejo para a avaliação da produção de leite seguiu o seguinte procedimento, o bezerro era colocado dentro da sala de ordenha e após o primeiro contato com o úbere da vaca já era contido de forma a não ingerir leite e se houvesse alguma ingestão de leite esta era desconsiderada por ser um erro possível a todas as vacas. Assim todos os quartos foram ordenhados mecanicamente na ordenha da manhã e na ordenha da tarde.

Foram coletadas amostras para fins de análise dos teores de proteína bruta, gordura, lactose, extrato seco total, extrato seco desengordurado e contagem de células somáticas no leite segundo a metodologia descrita pelo International Dairy Federation (1996). Estas amostras foram coletadas através de dispositivo acoplado à ordenhadeira, sendo coletado aproximadamente $300 \mathrm{~mL}$, no $21^{\circ}$ dia de cada período experimental, na ordenha da manhã e da tarde, fazendo-se amostras compostas, que foram acondicionadas em fracos plásticos com conservante (Bronopol ${ }^{\circledR}$ ), mantidas entre 2 e $6^{\circ} \mathrm{C}$, e encaminhadas para o Laboratório de Análises de Qualidade de Leite da Embrapa Gado de Leite, em Juiz de Fora, Minas Gerais.

A produção de leite corrigida (PLC) para 3,5\% de gordura foi calculada segundo Sklan et al. (1992), pela seguinte fórmula: 
PLC $=(0,432+0,1625 \times \%$ gordura do leite $) \times$ produção de leite em $\mathrm{kg} /$ dia.

Os resultados foram submetidos à análise de variância e teste de média (Tukey), adotando-se o nível de significância de 5\%, utilizando-se o programa SAEG, versão 8.1 (UFV, 2000). O modelo matemático do experimento foi o seguinte:

Yijk $=\mu+t i+b j+e i j k$

em que: Yijk = resposta experimental sobre o tratamento i, na repetição $\mathrm{k}$ do bloco j; $\mu$ = constante geral ou média geral; $\mathrm{ti}=$ efeito relativo ao tratamento $\mathrm{i} ; \mathrm{bj}=$ efeito relativo ao bloco j; eijk = erro aleatório, associado a cada observação, pressuposto NID $\left(0 ; \sigma^{2}\right)$.

\section{Resultados e Discussão}

Aumentos no nível de concentrado e de proteína bruta proporcionaram maior consumo de matéria seca total. A utilização de 46,8\% de concentrado e 16,0\% de proteína bruta na dieta total levou a um consumo de matéria seca total de 15,8 kg/dia, diferente dos demais níveis de concentrados e proteína bruta avaliados (Tabela 4). Esse maior consumo de matéria seca no nível de concentrado e de proteína bruta mais elevados provavelmente foi ocasionado pelo aumento da densidade da dieta total com a redução do tamanho de partículas, levando a maior taxa de passagem no trato gastrointestinal. Segundo Owens \& Goetsch (1993), aumentos da participação de grãos na dieta elevam o consumo, devido a uma maior densidade física do alimento, da diminuição do tamanho de partícula e dos reflexos na velocidade de passagem.
Outro ponto a ser analisado é o aumento no nível de proteína bruta nas dietas quando utilizados os maiores níveis de concentrado, uma vez que os maiores níveis de proteína bruta na dieta poderiam aumentar o consumo de matéria seca total, por proporcionar dietas de mais fácil digestão ou maior taxa de digestão. Pereira et al. (2005) avaliaram níveis crescentes de proteína bruta no concentrado (entre 13 e $17 \%$ da dieta total) para vacas de leite e notaram aumento no consumo de matéria seca com o aumento de proteína bruta na dieta. Lucci et al. (1999), trabalhando com um nível crescente de concentrado em dietas para vacas de leite, também observaram aumento no consumo de matéria seca quando aumentaram a quantidade de concentrado de 30 para $60 \%$, fato que pode estar relacionado a fatores metabólicos, como melhora na digestibilidade e aumento na taxa de passagem. LlamasLamas \& Combs (1991) citaram que o aumento no nível de concentrado em dietas para bovinos aumenta a ingestão de matéria seca.

O maior nível de concentrado e de proteína bruta levou a um maior consumo $(\mathrm{P}<0,05)$ também de proteína bruta, extrato etéreo, matéria orgânica, carboidratos totais, carboidratos não fibrosos e nutrientes digestíveis totais (Tabela 4). A falta de significância entre as dietas avaliadas para o consumo de fibra em detergente neutro pode ser explicada pela redução deste tipo de fibra na dieta total à medida que se aumenta o nível de concentrado e o teor de proteína bruta (Tabela 3), assim, ao aumentar o consumo de matéria seca total a ingestão de fibra em detergente neutro tende a se igualar entre as dietas experimentais.

Tabela 4 - Consumos médios diários em kg/dia e em porcentagem do peso vivo em função das dietas avaliadas

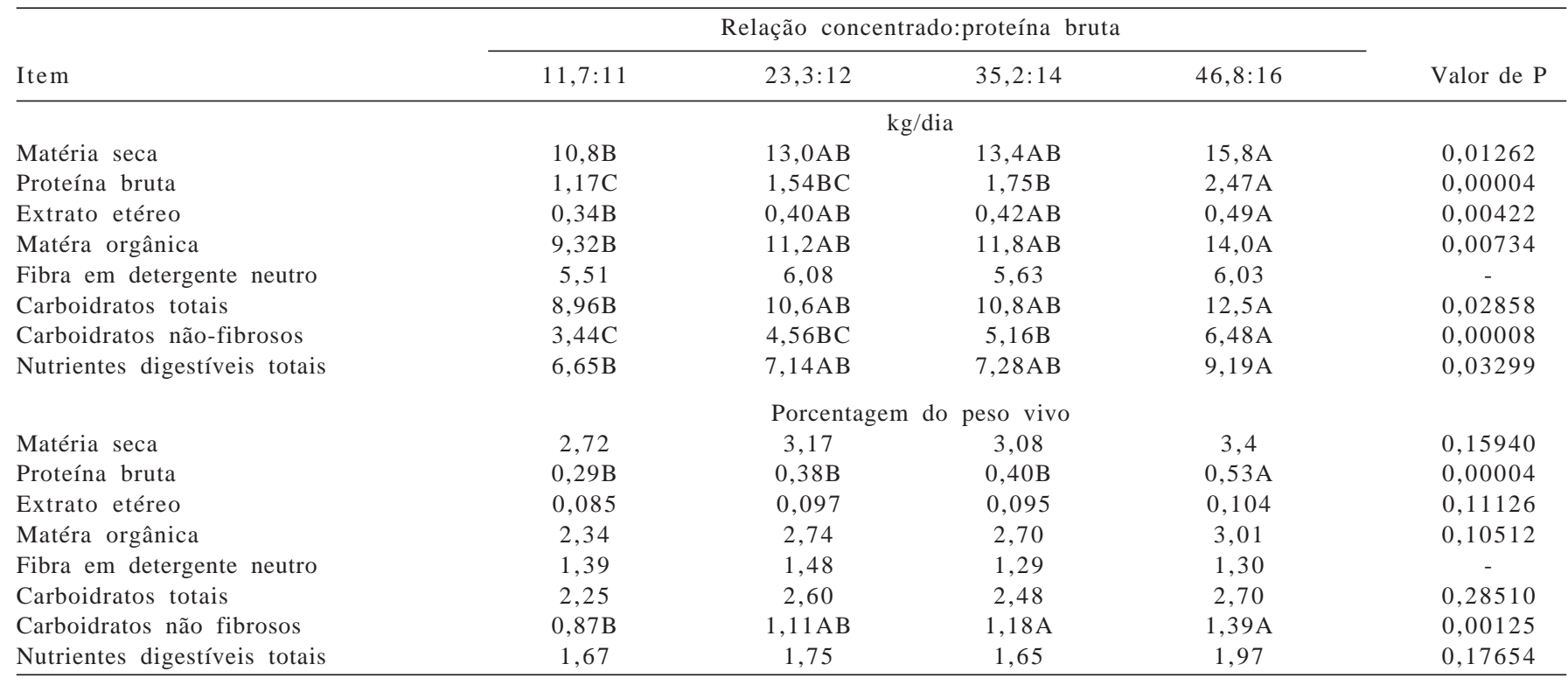

Médias na mesma linha seguidas por mesma letra maiúscula não diferem entre si ao nível de 5,0\% de significância pelo teste Tukey. 
Utilizando-se o indicador interno fibra em detergente neutro indigestível e saquinhos de Ankon, determinaram-se os coeficientes de digestibilidades dos nutrientes. À medida que foram acrescentados maiores níveis $\mathrm{dE}$ concentrado (Tabela 5) e proteína bruta nas dietas, o coeficiente de digestibilidade da matéria seca não diferiu entre as dietas experimentais testadas, provavelmente em virtude da boa qualidade da silagem de sorgo e dos concentrados utilizados.

O coeficiente de digestibilidade da proteína bruta foi influenciado pelos maiores níveis de concentrado e proteína bruta da dieta $(\mathrm{P}<0,05)$, onde a dieta com $46,8 \%$ de concentrado e $16,0 \%$ de proteína bruta proporcionou o maior coeficiente de digestibilidade da proteína bruta. A elevação do coeficiente de digestibilidade da proteína bruta pode estar relacionada à melhora na composição bromatológica das dietas, como redução dos teores de nitrogênio insolúvel em detergente neutro e em detergente ácido e lignina (Tabela 3). Assim, o aumento na taxa de passagem, que leva a uma redução no coeficiente de digestibilidade, seria compensado pela presença de uma dieta mais digestível. Os compostos nitrogenados em forma de nitrogênio insolúvel em detergente neutro são resistentes e praticamente indigestíveis no rúmen e geralmente estão associados à lignina e a outros compostos de difícil degradação (Licitra et al., 1996).

Nas dietas com maiores nível de concentrado e de proteína bruta não houve maiores consumos de fibra em detergente neutro, porém a excreção fecal foi maior, isso leva a um menor tempo para degradação da fibra e consequentemente redução na digestibilidade deste nutriente, explicando o maior coeficiente de digestibilidade da fibra em detergente neutro $(\mathrm{P}<0,05)$ nas dietas com menores níveis de concentrado e de proteína bruta. Já para o valor dos nutrientes digestíveis totais observados não houve efeito significativo em função do nível de concentrado e de proteína bruta acrescidos à dieta.
Esses resultados distorcem dos encontrados na literatura, de maiores coeficientes de digestibilidade em maiores níveis de concentrado e de proteína bruta nas dietas. Pereira et al. (2005), trabalhando com níveis crescentes de proteína bruta em vacas de leite mestiças (12,7 a 16,9\% da matéria seca total da dieta), observaram efeito linear positivo dos níveis de proteína bruta sobre as digestibilidades da matéria seca, matéria orgânica, proteína bruta e fibra em detergente neutro. Vários autores relataram que a utilização de níveis crescentes de proteína bruta resultou em aumentos nas digestibilidades da matéria seca, matéria orgânica, proteína bruta e fibra em detergente ácido (Cunningham et al., 1996; Valadares et al., 1997; Broderick, 2003). Sniffen et al. (1993) e Wilson \& Kennedy (1996) afirmaram que a ingestão de compostos nitrogenados é importante para atender aos requerimentos microbianos, sobretudo daqueles agentes que digerem a fibra, resultando em aumento do consumo e do desaparecimento do alimento. Broderick (2003) não observou variação na digestibilidade aparente da matéria seca e orgânica conforme o aumento de proteína bruta dietética, mas notou que as digestibilidades da fibra em detergente neutro e ácido elevaram linearmente. Porém, nenhum destes autores trabalhou com vacas da raça Gir linhagem leiteiro.

A produção de leite em $\mathrm{kg} / \mathrm{dia}$ foi maior $(\mathrm{P}<0,05)$ nos animais que receberam as dietas com maiores níveis de concentrado e de proteína bruta, contudo, não houve diferenças na produção entre aqueles que receberam as dietas com 23,3; 35,2 e 46,8\% de níveis de concentrado e 12,$0 ; 14,0$ e $16,0 \%$ de proteína bruta, respectivamente (Tabela 6). Esses dados confirmam normalmente a baixa eficiência dos bovinos em produzir leite com o aumento do nível de concentrado na dieta (Lana et al., 2005), pois com a utilização de 23,3:12 (\% de concentrado: \% de proteína bruta, base da matéria seca) nas dietas das vacas Gir a produção de leite foi semelhante ao das vacas Gir que receberam uma dieta com 46,8\% de concentrado e de $16,0 \%$ de proteína

Tabela 5 - Médias ajustadas para os coeficientes de digestibilidade aparente e excreção fecal em função das dietas experimentais avaliadas

\begin{tabular}{|c|c|c|c|c|c|}
\hline \multirow[b]{2}{*}{ Coeficiente de digestibilidade (\%) } & \multicolumn{4}{|c|}{ Níveis concentrado:proteína bruta } & \multirow[b]{2}{*}{ Valor de $\mathrm{P}$} \\
\hline & $11,7: 11$ & $23,3: 12$ & $35,2: 14$ & $46,8: 16$ & \\
\hline Matéria seca & 54,7 & 50,3 & 49,2 & 54,5 & 0,06821 \\
\hline Proteína bruta & $54,5 \mathrm{~B}$ & $54,1 \mathrm{~B}$ & $53,0 \mathrm{~B}$ & $61,4 \mathrm{~A}$ & 0,00380 \\
\hline Extrato etéreo & 77,3 & 72,8 & 76,2 & 71,9 & 0,16299 \\
\hline Fibra em detergente neutro & $42,7 \mathrm{~A}$ & $37,5 \mathrm{~B}$ & $36,2 \mathrm{~B}$ & $37,7 \mathrm{AB}$ & 0,01238 \\
\hline Carboidratos totais & 58,1 & 52,8 & 51,1 & 56,4 & 0,07275 \\
\hline Carboidratos não-fibrosos & $82,7 \mathrm{~A}$ & $73,1 \mathrm{AB}$ & $67,0 \mathrm{~B}$ & $73,6 \mathrm{AB}$ & 0,03062 \\
\hline Matéria orgânica & 53,8 & 48,5 & 47,8 & 53,9 & 0,06371 \\
\hline Nutrientes digestíveis totais observados & 58,0 & 53,1 & 52,1 & 57,4 & 0,06867 \\
\hline Excreção fecal (kg/animal/dia) & $4,92 \mathrm{C}$ & $6,47 \mathrm{~B}$ & $6,81 \mathrm{~B}$ & $7,26 \mathrm{~A}$ & 0,03359 \\
\hline
\end{tabular}

Médias na mesma linha seguidas por mesma letra maiúscula não diferem entre si ao nível de 5,0\% de significância pelo teste Tukey. 
Tabela 6 - Médias ajustadas para produção de leite e produção de leite corrigida, composição de sólidos do leite, peso vivo e condição de escore corporal

\begin{tabular}{|c|c|c|c|c|c|}
\hline \multirow[b]{2}{*}{ Item } & \multicolumn{4}{|c|}{ Nível de concentrado:proteína bruta } & \multirow[b]{2}{*}{$\mathrm{P}$} \\
\hline & $11,7: 11$ & $23,3: 12$ & $35,2: 14$ & $46,8: 16$ & \\
\hline Produção de leite (kg/dia) & $9,7 \mathrm{~B}$ & $12,7 \mathrm{~A}$ & $11,4 \mathrm{AB}$ & $12,0 \mathrm{~A}$ & 0,00681 \\
\hline Proteína bruta (\%) & $3,17 \mathrm{C}$ & $3,24 \mathrm{BC}$ & $3,55 \mathrm{AB}$ & $3,57 \mathrm{~A}$ & 0,00522 \\
\hline Gordura (\%) & 4,58 & 3,88 & 4,12 & 4,08 & - \\
\hline Lactose (\%) & 4,55 & 4,56 & 4,69 & 4,57 & - \\
\hline Peso vivo pré $(\mathrm{kg})$ & 402 & 402 & 426 & 445 & 0,39594 \\
\hline Peso vivo (kg) & 398 & 409 & 442 & 465 & 0,10709 \\
\hline Variação de peso vivo (kg/dia) & $-0,15 B$ & $0,18 \mathrm{AB}$ & $0,26 \mathrm{~A}$ & $0,43 \mathrm{~A}$ & 0,00654 \\
\hline Escore corporal pré & 5,60 & 5,40 & 4,80 & 5,20 & - \\
\hline Escore corporal & 5,33 & 5,80 & 5,80 & 6,27 & 0,25484 \\
\hline
\end{tabular}

Médias na mesma linha seguidas por mesma letra maiúscula não diferem entre si a 5,0\% de significância pelo teste Tukey.

bruta. Analisando a produção de leite corrigido para gordura, não há diferença na produção de leite entre as dietas.

Houve aumento $(\mathrm{P}<0,05)$ no teor de proteína bruta do leite com o incremento dos níveis de concentrado e proteína bruta nas dietas, onde o maior teor de proteína no leite (3,57\%) foi em função do maior nível de concentrado e de proteína bruta da dieta $(46,8: 16)$. O aumento do teor de concentrado na ração aumenta a quantidade de substrato para a fermentação ruminal e, portanto, aumenta a quantidade de proteína microbiana produzida. A proteína microbiana é a melhor fonte proteica disponível para a síntese de proteína do leite ou tecido animal, e em segundo lugar o farelo de soja convencional por seu balanço adequado para a maioria dos aminoácidos essenciais (Santos, 2006). Dessa forma, o aumento do nível de concentrado com o aumento de proteína bruta na dieta total, provavelmente aumentou a quantidade de proteína microbiana no rúmen, o que também proporciona uma boa relação lisina metionina (Lis:Met). A relação lisina:metionina de 3:1 na proteína metabolizável tem se mostrada adequada para maximizar o desempenho de vacas leiteiras (Santos, 2006).

Conforme Peres (2001), semelhante à gordura, o teor de proteína do leite é fortemente influenciado pela genética do animal, todavia com amplitude de variação muito menor, na ordem de 0,1 a 0,2\% dependendo da nutrição animal. Essa pequena possibilidade de variação pode ser explicada pelo fato de que, em contraste com a síntese de gordura pela glândula mamária, a síntese de proteína é muito mais restrita em termos de precursores utilizados e na sequência de inclusão por ocasião da formação de moléculas. As unidades formadoras de proteínas são os aminoácidos, e a deficiência de umúnico aminoácido impede a formação de toda molécula. Assim, a utilização de concentrados como medida para aumentar o teor de proteína do leite é um recurso caro e que geralmente não compensa, pois o aumento da ingestão de energia por meio de fontes de carboidratos pode aumentar a produção e a porcentagem de proteína do leite. Entretanto, cerca de $85 \%$ do aumento da produção de proteína do leite se dá pelo aumento na quantidade de leite produzido, e apenas $15 \%$ da resposta está relacionada a aumentos na porcentagem de proteína do leite (Peres, 2001).

Ainda segundo Peres (2001), incrementos no teor de proteína bruta das dietas têm pouca influência no aumento de proteína do leite. De acordo com um trabalho feito por Emery (1978), para cada aumento no teor de proteína da dieta, variando de 9 a $17 \%$, houve aumento de apenas $0,02 \%$ no teor de proteína do leite. Pereira et al. (2005), utilizando níveis crescentes de proteína bruta em dietas de vacas de leite, não encontraram efeito significativo no teor de proteína do leite. Deresz (2001), com os objetivos de estudar os efeitos do concentrado sobre a produção e composição do leite de vacas mestiças Holandês $\times$ Zebu, utilizando dietas com 0 e 2,0 kg de concentrado/vaca/dia, encontrou aumento de $0,2 \%$ no teor de proteína do leite com a utilização de $2,0 \mathrm{~kg}$ de concentrado.

Os maiores aumentos do nível de concentrado e de proteína bruta nas dietas proporcionaram maior variação de peso vivo positivo $(\mathrm{P}<0,05)$, a qual foi semelhante entre os três maiores níveis de concentrado e proteína bruta (Tabela 6). Na dieta com $11,7 \%$ de concentrado e de $11,0 \%$ de proteína bruta com base da matéria seca da dieta total verificou-se uma variação de peso vivo de $-0,15 \mathrm{~kg} / \mathrm{dia}$, ou seja, há uma perda de peso, dessa forma, infere-se que estes níveis deveriam ser evitados. Dessa forma, mesmo que grandes aumentos na quantidade de concentrado não signifiquem grandes aumentos na produção de leite, o uso de concentrado em certos níveis permite o equilíbrio entre produção de leite, ganho de peso, intervalo de parto e 
consequentemente melhor manejo e renda com este tipo de animal.

Não houve efeito significativo das dietas sobre as eficiências de produção de leite e produção de leite corrigida em função do consumo de matéria seca (Tabela 7). A resposta produtiva de leite em função do consumo de matéria seca total acima da dieta com $11,7 \%$ de concentrado reduziu com o aumento no nível de concentrado, estando de acordo com Bargo et al. (2003), que reportam aumento decrescente na produção de leite em resposta ao aumento no consumo de concentrado. Lekchom et al. (1989), citados por Gomide (1998), também verificaram decréscimos na produção de leite com o aumento no fornecimento de concentrado e também decréscimo progressivo na renda líquida para níveis de suplementação acima de 2,5 kg de concentrado/animal/dia. Assim a resposta produtiva mais adequada ao nível de concentrado e de proteína bruta utilizado nas dietas foi de $23,3 \%$ de concentrado e de $12,0 \%$ de proteína bruta na dieta total, com base na matéria seca, por proporcionar maior resposta produtiva.

Tabela 7 - Médias ajustadas para a eficiência de produção de leite e produção de leite corrigida em relação ao consumo de matéria seca total e resposta produtiva

\begin{tabular}{|c|c|c|c|c|c|}
\hline \multirow[b]{2}{*}{ Item } & \multicolumn{4}{|c|}{ Nível de concentrado:proteína bruta } & \multirow[b]{2}{*}{ Valor de $\mathrm{P}$} \\
\hline & $11,7: 11$ & 23,3:12 & $35,2: 14$ & $46,8: 16$ & \\
\hline Produção de leite/consumo de matéria seca $(\mathrm{kg} / \mathrm{kg})$ & 0,91 & 0,98 & 0,85 & 0,75 & 0,05936 \\
\hline Resposta produtiva $^{2}$ (kg de leite/kg de concentrado acima da dieta 11,7:11) & - & 1,36 & 0,65 & 0,46 & - \\
\hline
\end{tabular}

Médias na mesma linha seguidas por mesma letra maiúscula não diferem entre si ao nível de 5,0\% de significância pelo teste Tukey.

${ }^{1}$ Diferencial de produção de leite/diferencial de consumo de matéria seca total das dietas com 23,3; 35,2; e 46,8\% de concentrado em relação à dieta com $11,7 \%$ de concentrado.

\section{Conclusões}

A utilização de maiores níveis de concentrado e proteína bruta proporcionaram maiores ingestões de matéria seca total e de nutrientes, porém, não proporcionaram produção de leite mais elevadas. Assim, para vacas da raça Gir da linhagem leiteira mantidas em condições semelhantes às deste estudo, recomendam-se dieta com 23,3\% de concentrado e $12,0 \%$ de proteína bruta na dieta total, por proporcionar ganhos de condição corporal semelhantes aos obtidos em níveis mais elevados de concentrado e proteína bruta na dieta total e por proporcionar maior resposta produtiva de leite.

\section{Referências}

AGRICULTURAL RESEARCH COUNCIL - ARC. The nutrient requirements of farm Livestock. Farnham Royal: Commonwealth Agricultural Bureaux, 1980. 350p.

BARGO, F.; MULLER, L.D.; KOLVER, E.S. et al. Invited review: Production and digestion of supplemented dairy cows on pasture. Journal of Dairy Science, v.86, p.1-42, 2003.

BRODERICK, G.A. Effects of varying dietary protein and energy levels on the production of lactating dairy cows. Journal of Dairy Science, v.86, n.4, p.1370-1381, 2003.

CASALI, A.O.; DETMANN, E.; VALADES FILHO, S.C. et al. Influência do tempo de incubação e do tamanho de partículas sobre os teores de compostos indigestíveis em alimentos e fezes bovinas obtidos por procedimentos in situ. Revista Brasileira de Zootecnia, v.37, n.2, p.335-342, 2008.
COCHRAN, R.C.; ADAMS, D.C.; WALLACE, J.D. et al. Predicting digestibility of diets with internal markers: Evaluation of four potential markers. Journal of Animal Science, v.63, p.1476-1483, 1986.

CUNNINGHAM, K.D.; CECAVA, M.J.; JOHNSON, T.R. et al. Influence of source and amount of dietary protein on milk yield by cows in early lactation. Journal of Dairy Science, v.79, n.4, p.620-630, 1996.

DERESZ, F. Produção de leite de vacas mestiças Holandês x Zebu em pastagem de capim-elefante, manejada em sistema rotativo com e sem suplementação durante a época das chuvas. Revista Brasileira de Zootecnia, v.30, n.1, p.197-204, 2001.

EMERY, R.S. Feeding for increased milk protein. Journal of Dairy Science, v.61, p.825, 1978.

FERREIRA, M.B.D.; LOPES, B.C.; AZEVEDO, N.A. et al. Escore corporal e manejo reprodutivo de vacas gir leiteiro. Revista Gir Leiteiro, Ano 5, n.5, p.46-54, 2005.

GOMIDE, J.A. Fatores da produção de leite a pasto. In: CONGRESSO NACIONAL DOS ESTUDANTES DE ZOOTECNIA, 1998, Viçosa, MG. Anais... Viçosa, MG: Suprema Gráfica, 1998. p.1-32.

INTERNATIONAL DAIRY FEDERATION - IDF. Whole milk determination of milkfat, protein and lactose content. Guide fir the operation of mid-infra-red instuments. Bruxelas, 1996. 12p. (IDF Standard 141 B).

LANA, R.P.; GOES, R.H.T.B.; MOREIRA, L.M. et al. Application of Lineweaver-Burk data transformation to explain animal and plant performance as a function of nutrient supply. Livestock Production Science, v.98, p.219-224, 2005.

LICITRA, G.; HERNANDEZ, T.M.; VAN SOEST, P.J. Standardization of procedures for nitrogen fractionation of ruminant feeds. Animal Feed Science and Technology, v.57, p.347-358, 1996.

LLAMAS-LAMAS, G.; COMBS, D.K. Effect of forage to concentrate ratio and intake level on utilization of early vegetative alfalfa silage by dairy cows. Journal of Dairy Science, v.74, p.526-536, 1991. 
LUCCI, C.S.; RODRIGUES, P.H.M.; MELOTTI, L. [1999]. Efeitos da lasalocida sódica e da proporção concentrado/volumoso sobre o desempenho produtivo de vacas lactantes. Brazilian Journal of Veterinary Research and Animal Science [online], v.36, n.1, doi: 10.1590/S1413-95961999000100010

NATIONAL RESEARCH COUNCIL - NRC. Nutrient requirements of dairy cattle. 6.ed. Washington, D.C.: National Academy of Sciences, 1989. 158p.

NATIONAL RESEARCH COUNCIL - NRC. Nutrient requirements of dairy cattle. 7.ed. Washington, D.C.: National Academy of Sciences, 2001. 381p.

OLIVEIRA, A.S.; CAMPOS, J.M.S.; LANA, R.P. Uso do conceito de análise marginal para estimar o nível ótimo de suplementação com alimentos concentrados para vacas de leite em pastagens. In: LANA, R.P. (Ed.) Respostas biológicas aos nutrientes. Viçosa, MG: Editora CPD, 2007. p.155-177.

OWENS, F.N.; GOETSCH, A.L. Fermentación ruminal. In: CHURCH, D.C. (Ed.) El ruminante, fisiologia digestiva y nutrición. Zaragoza: Acríbia, 1993. p.159-190.

PEREIRA, M.L.A.; VALADARES FILHO, S.C.; VALADARES, R.F.D. et al. Consumo, digestibilidade aparente total, produção e composição do leite em vacas no terço inicial da lactação alimentadas com níveis crescentes de proteína bruta no concentrado. Revista Brasileira de Zootecnia, v.34, n.3, p.1029-1039, 2005.

PERES, J.R. O leite como ferramenta do monitoramento nutricional. In: GONSÁLEZ, F.H.D.; DÜRR, J.W.; FONTANELI, R.S. (Eds.) Uso do leite para monitorar a nutrição e o metabolismo de vacas leiteiras. Porto Alegre: 2001. p.30-45.
SANTOS, F.A.P. Metabolismo de proteínas. In: BERCHIELLI, T.T.; PIRES, A.V.; OLIVEIRA, S.G. (Eds.) Nutrição de ruminantes Jaboticabal: Funep, 2006. 583p.

SILVA, D.J.; QUEIROZ, A.C. Análise de alimentos (métodos químicos e biológicos). Viçosa, MG, UFV, Imprensa Universitária, 2002. 235p.

SKLAN, D.; ASHKENAZI, R.; BRAUN, A. et al. Fatty acids, calcium soaps of fatty acids and cottonseeds fed to high yielding cows Journal of Dairy Science, v.75, p.2463-2472, 1992.

SNIFFEN, C.J.; O'CONNOR, J.D.; VAN SOEST, P.J. et al. A net carbohydrate and protein system for evaluating cattle diets: II. Carbohydrate and protein availability. Journal of Animal Science, v.70, p.3562-3577. 1992.

SNIFFEN, C.J.; BEVERLY, R.W.; MOONEY, C.S. et al. Nutrient requirement versus supply in dairy cow: strategies to account for variability. Journal of Dairy Science, v.76, n.10, p.3160-3178, 1993.

UNIVERSIDADE FEDERAL DE VIÇOSA - UFV. SAEG - Sistema de Análises Estatísticas e Genéticas. Versão 8.0. Viçosa, MG, 2000. 142p. (manual do usuário).

VALADARES, R.F.D.; GONÇALVES, L.C.; RODRIGUEZ, N.M. et al. Níveis de proteína em dietas de bovinos. 1. Consumo e digestibilidades aparentes totais e parciais. Revista Brasileira de Zootecnia, v.26, n.6, p.1252-1258, 1997.

WILSON, J.R.; KENNEDY, P.M. Plant and animal constraints to voluntary feed intake associated with fibre characteristics and particle breakdown and passage in ruminants. Australian Journal of Agriculture Research, v.47, n.1, p.199-225, 1996. 